\title{
Noise levels in dental schools
}

\author{
J. C. Sampaio Fernandes ${ }^{1}$, A. P. O. Carvalho ${ }^{2}$, M. Gallas ${ }^{3}$, P. Vaz ${ }^{4}$ and P. A. Matos ${ }^{5}$ \\ ${ }^{1}$ Department of Fixed Prosthesis, Faculty of Dentistry, University of Porto, ${ }^{2}$ Laboratory of Acoustics, Department of Civil Engineering, Faculty of \\ Engineering, University of Porto, ${ }^{3}$ University of Porto, Porto, Portugal, ${ }^{4}$ Faculty of Medicine and Dentistry, School of Dentistry, University of Santiago de \\ Compostela, Santiago de Compostela, Spain, ${ }^{5}$ Department of Human Anatomy and Human Genetics, Faculty of Dentistry, University of Porto, Porto, \\ Portugal
}

Objective: To measure and analyse noise levels in the learning-teaching activities at the Dental School of the University of Porto (Portugal).

Materials and methods: Sound levels were measured in five different practice areas and laboratories, selected as representative of a variety of learning-teaching activities. The noise levels were determined using a precision sound level meter that was positioned at ear level and at $1 \mathrm{~m}$ distance from the operator.

Results: The noise levels registered vary between 60 and 99 $\mathrm{dB}(\mathrm{A})$ and are similar to the data of other international studies. The results recorded differences in sound levels when the equipment was merely turned on and during cutting operations. Differences between brand new and used equipment were also noted. It appears that hearing damage risk may be lesser amongst dentists who use brand new equipment.

Conclusion: The noise levels detected in this study are considered to be close to the limit of risk of hearing loss.

Key words: noise level; dentistry; dental education; hearing loss; occupational hazards.

(C) Blackwell Munksgaard, 2006

Accepted for publication, 27 October 2005
L EARNING-TEACHING activities at a dental school require the use of diverse equipments that emit noise. The noise levels produced by the different mechanical equipment (clinical hand-pieces, turbines, laboratory engines, etc.) inherent to these educational activities are the main indicators of acoustic comfort in these areas. Long exposure to high noise levels may cause adverse effects and in some cases lead to loss of hearing.

Essentially, noise is characterised by its sound level and frequency. Audible sound consists of pressure waves in air with a frequency range of $20 \mathrm{~Hz}$ to $20 \mathrm{kHz}$. Human hearing does not respond uniformly to all frequencies. This is taken into account when an audiometric standard is set. Sounds measured in frequency bands may be A-weighted or adjusted to account for the approximate frequency dependence of human hearing. The result is a single-number descriptor, the A-weighted sound level in decibels $\mathrm{dB}(\mathrm{A})$. Thus the values that relate sound measurements to human perception are $\mathrm{dB}(\mathrm{A})$ where the letter $\mathrm{A}$ stands for the use of a specific type of electric filter. This filter adapts the sound level meter to a human response that limits decreases real sound to very low and very high frequencies where the human ear has lower sensitivity.
In dental practical classes, the acoustic environment is characterised by high noise levels in relation to other teaching areas, due to the exaggerated noise produced by some of these devices and to the use of dental equipment by many users at the same time. This situation is aggravated when the classrooms have hard surfaces which act as noise reflectors, as is usually the case. Therefore, it should be guaranteed that, in school buildings of this type, sound levels are not detrimental to learning activities. Long exposure to high noise levels by students and lecturers has an obvious negative effect. It is well known that high sound levels have a negative effect on extra-auditory systems with physical consequences (quickened pulse, increase in blood pressure, constriction of blood vessels, etc.) and psychical consequences (nervousness, mental fatigue and emotional frustration, low productivity, etc.). These effects occur especially with noise levels above $80 \mathrm{~dB}(\mathrm{~A})$ and are dependent on the intensity, the distance to the source, the total duration of the noise, the age of the individual and his/her physical condition and sensitivity $(1,2)$. Also, it is commonly known that exposure to noise can induce loss of hearing. Noise-induced hearing loss proceeds in three stages. In the first stage, sensory cells within the cochlea are killed by excessive noise exposure. The 
cells do not regenerate and are replaced by scar tissue. In the second stage, after weeks or years of excessive exposure, loss of hearing can be detected audiometrically, although speech comprehension is still not significantly affected. With prolonged noise exposure, the loss of hearing spreads to the lower pitches necessary for understanding speech. In this third stage, the patient usually becomes aware of the problem and may seek medical attention (3).

It is therefore essential to control noise in learning environments, not forgetting that acoustic comfort depends not only on the control of the emitted sound levels but also on the acoustic characteristics of the classrooms.

The classrooms at the University of Porto Dental School are a clear example of noisy learning areas, because there are high noise levels and the materials that were used in the construction of the building are not sufficiently noise absorbent. This study evaluates noise levels in these learning-teaching areas so as to analyse the risk of hearing impairment.

\section{Method}

The acoustic environment was measured and analysed during classes in clinic and pre-clinic classrooms and laboratories at the Dental School of the University of Porto (Portugal).

The sound levels were measured with a precision sound level meter (Bruel \& Kjaer 2260, Naerum, Denmark) and a half-inch microphone in the different learning-teaching areas. In each area a microphone was placed at ear level and at a distance of $1 \mathrm{~m}$ from a main noise source to simulate the auditory position of the operator (dentist). The measurements were taken with the equipment only turned on (without cutting) and during cutting operations (on teeth, metal and acrylic resin). Some of the evaluated clinical equipment was brand new whilst the rest had had a year or more of prolonged use.

The learning-teaching areas and the activities analysed in this study were the following:

Prosthesis Laboratory - With the engine turned on (without cutting) and during cutting operations on metal and acrylic resin; with the aspirator turned on only and then used together with the engine during the same cutting operations.

Gypsum Laboratory - Activities of cutting and vibration of gypsum.

Annexe of the Gypsum Laboratory - Activities of cutting and burnishing of gypsum simultaneously with the suction pump turned on.

Pre-clinic - Use of a brand new turbine (air-rotor hand-piece) turned on only and during cutting operations on teeth and acrylic resin; use of a brand new contra-angle hand-piece (low speed handpiece); use of a brand new straight hand-piece.

Clinic - Use of brand new and used turbines turned on only and during cutting operations on teeth and acrylic resin; use of brand new and used contraangle hand-piece, and use of a straight hand-piece under the same conditions.

The characteristics of the equipment measured in each learning-teaching area are noted in Table 1.

The sound level meters employed were the $L_{\mathrm{A}(\mathrm{eq})}$ (equivalent to continuous sound level in a specific time interval), $L_{\mathrm{pk}(\max \mathrm{p})}$ (highest value) and $L_{\mathrm{E}}$ (level

TABLE 1. Characteristics of the equipment measurement

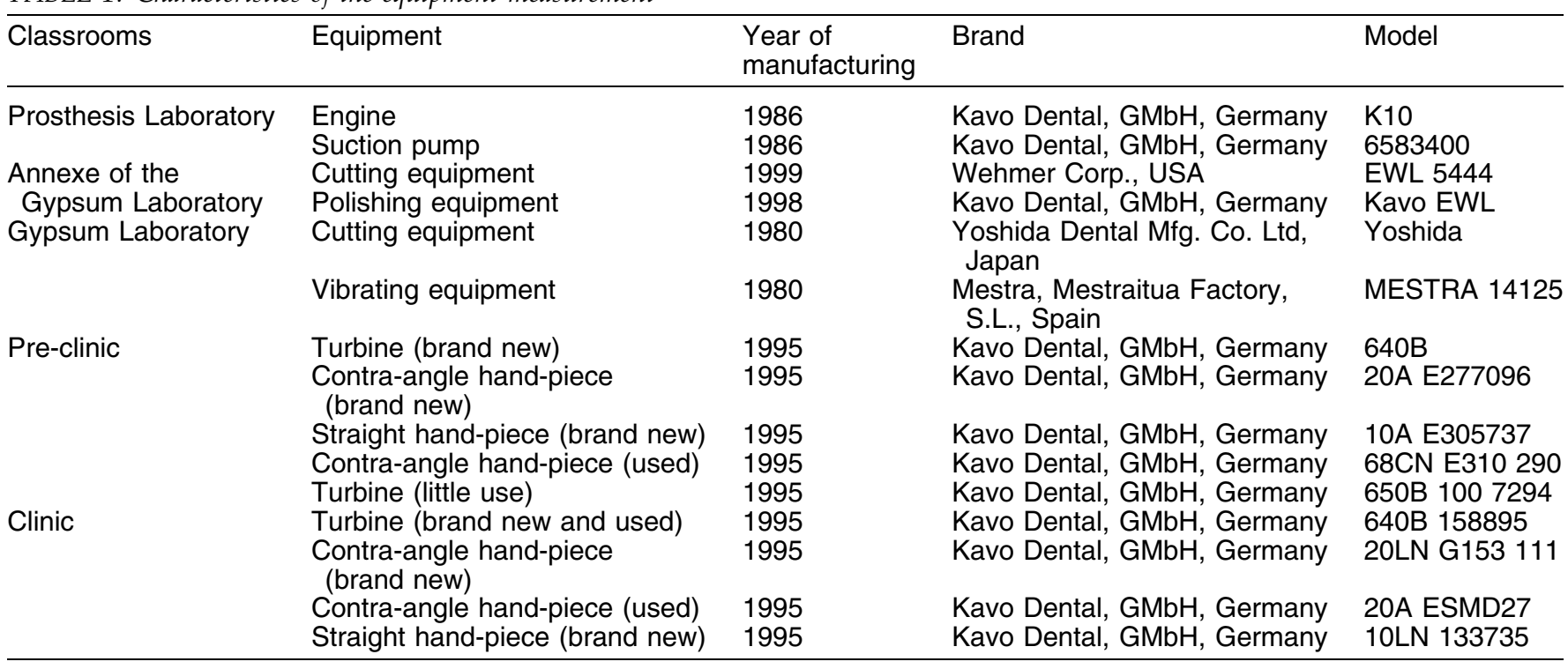


Sampaio Fernandes et al.

TABLE 2. Sound levels $\left[L_{\mathrm{A}(\mathrm{eq})}\right]$ measured in different classrooms and during different learning-teaching activities

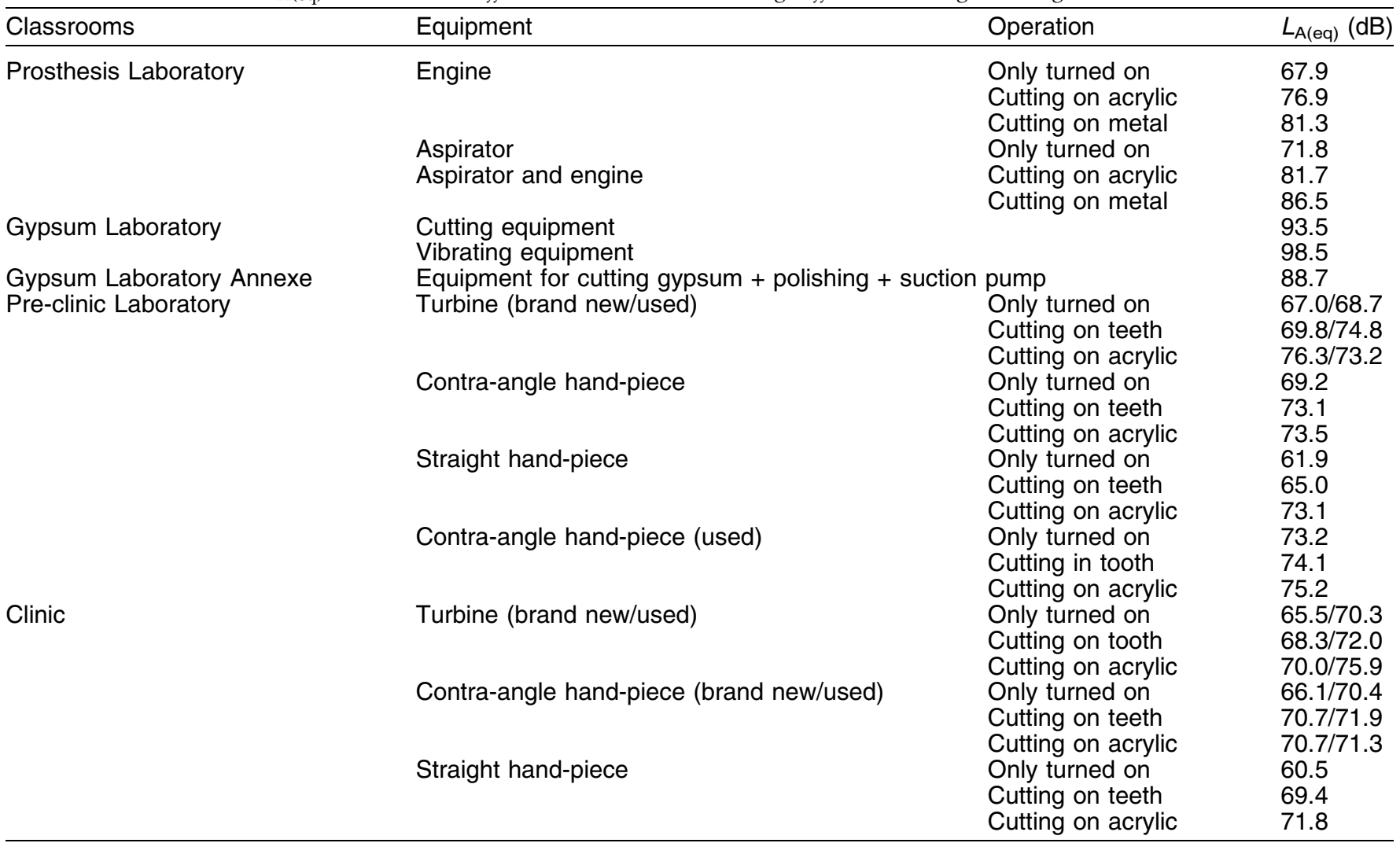

of noise exposure) to be quantified. It also measured the noise spectra in frequency bands and the levels of sound pressure.

As well as measuring the overall equipment sound levels during classes in the Pre-clinic and Clinic areas and in the Prosthesis Laboratory, the typical background noise was also measured. The noise criterion (NC) values (4) and daily personal noise exposure $\left(L_{\mathrm{EP}, \mathrm{d}}\right)$ were also recorded.

\section{Results}

The results displayed in Table 2 show that the sound levels vary between 60 and $99 \mathrm{~dB}(\mathrm{~A})$, being very high in the Gypsum Laboratory where values of $\mathrm{L}_{\mathrm{A}(\mathrm{eq})}$ were from 94 to $99 \mathrm{~dB}(\mathrm{~A})$. The noisiest areas analysed were the Gypsum and Prosthesis Laboratories.

The differences in the sound levels between brand new and used equipment were also recorded (Table 2). In general, the used equipment was noisier, between 1 and $6 \mathrm{~dB}(\mathrm{~A})$ more than the brand new and average of about $3 \mathrm{~dB}(\mathrm{~A})$ difference.

To quantify the acoustic disturbance introduced in the classrooms by noise originating from the clinical equipment, the values of the parameter NC (4) in each

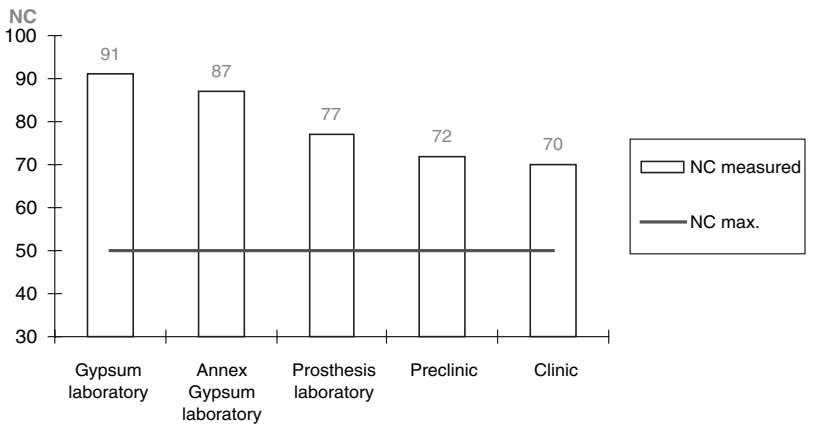

Fig. 1. Noise criterion (NC) values for each classroom and proposed maximum NC value for minimum comfort.

classroom were calculated (Fig. 1). The highest values $(70-91 \mathrm{~dB})$ were found in the Gypsum Laboratory.

\section{Discussion}

It is well known that dentists experience gradual hearing loss during their working life (5). The purpose of this study was to measure the frequency of sounds emitted in learning-teaching areas under different working conditions during classes. The sound levels detected in this study were similar to that detected in other international studies of noise in dental offices. The measured sound levels of the different equipment 


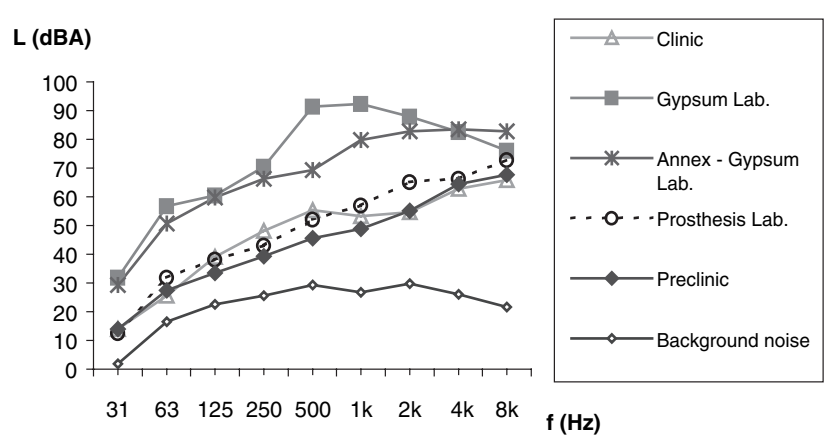

Fig. 2. Comparison of noise spectra (1/1 octave band) in classrooms with typical background noise [in $\mathrm{dB}(A)]$.

do not vary much to those found in other countries, for example the United Kingdom and Saudi Arabia, but in Portugal they seem to be slightly higher by +1 to $+5 \mathrm{~dB}(\mathrm{~A})(1,2)$. Sounds levels for the suction pump were $72 \mathrm{~dB}(\mathrm{~A})$ in Portugal, whereas in the United Kingdom they were $68-70 \mathrm{~dB}(\mathrm{~A})$. Sound levels for the turbine were $68-76 \mathrm{~dB}(\mathrm{~A})$ in Portugal whereas in the United Kingdom they were 70-75 $\mathrm{dB}(\mathrm{A})$ and in Saudi Arabia they were approximately $72 \mathrm{~dB}(\mathrm{~A})$; for the contra-angle hand-piece they were $69-75 \mathrm{~dB}(\mathrm{~A})$ in Portugal, but in the United Kingdom they were 72$75 \mathrm{~dB}(\mathrm{~A})$ and in Saudi Arabia they were approximately $68 \mathrm{~dB}(\mathrm{~A})$.

Also, the results showed that the sound levels measured during cutting activities were higher to those found when only turned on. The average value of the differences (cutting against only turned on) was equal to $+6 \mathrm{~dB}(\mathrm{~A})$, were values range from +1 to $+4 \mathrm{~dB}(\mathrm{~A})$. However, Bahannan (1) presented average values of $+10 \mathrm{~dB}(\mathrm{~A})$ in similar conditions of measurement in Saudi Arabia. Specifically, the noisiest cutting operation was on metal with $13 \mathrm{~dB}(\mathrm{~A})$ of average difference followed by cutting on acrylic resin $[+6 \mathrm{~dB}(\mathrm{~A})]$ and cutting on teeth $[+4 \mathrm{~dB}(\mathrm{~A})]$.

The analysis of the noise spectra of the tested equipment showed elevated sound pressure levels in the higher frequency bands (Fig. 2). The highest values were recorded in the Gypsum Laboratory probably due to the use of the suction pump that is not very common in other learning-teaching areas. The suction pump emits unpleasant sounds that could be the origin of typical psychical disturbances and 'irritability' caused in many people in this area, because this noise is very strident.

According to the classification proposed by Cavanaugh (4) the value of the suggested maximum NC for laboratories, clinics and classrooms is $50 \mathrm{~dB}$. All the evaluated areas presented an NC value higher than this maximum.
When the reference $\mathrm{NC}$ is equal to $50 \mathrm{~dB}$, the corresponding equivalent sound level is of about $56 \mathrm{~dB}(\mathrm{~A})$ and this noise level still allows a relaxed communication at a normal tone at $3 \mathrm{~m}$ (4). This seems adequate as the upper limit value in places of learning in dental schools.

Whilst in the Clinic, the sound level values for the brand new turbine were lower than the ones for the used turbine [approximately about $5 \mathrm{~dB}(\mathrm{~A})$ ], in the Pre-clinic the brand new turbine values were slightly higher to the ones for the used turbine (during cutting operations). This difference constitutes an exception, and it is justified by the fact that the used turbine in the Pre-clinic area is almost brand new as it is not frequently use in comparison. Although, according to other studies, high-speed dental air turbines are the most noisiest dental equipment of dental offices. Altinoz et al. (6) indicated that under any working conditions (under free working conditions without burs, with fissure burs, with flare burs, with round burs and with inverted cone burs) high-speed dental air turbines emit noise at frequencies that may cause hearing loss over time.

Noise-induced hearing loss develops slowly over the years, is caused by any exposure regularly exceeding a daily average of $85 \mathrm{~dB}(\mathrm{~A})$. However, the effects of occupational noise exposure cannot be separated from other causes of hearing loss. The degree of risk to the individual dentist depends on various factors: personal susceptibility, total daily exposure and patterns of use. In our study, the levels of daily personal noise exposure for lecturers and students were calculated by the standard expression:

$$
L_{\mathrm{A}(\mathrm{EP}, \mathrm{d})}=10 \log _{10}\left[\frac{1}{8} \sum_{k=1}^{k=n} T_{k} \cdot 10^{\left(0.1 L_{\mathrm{A}(\mathrm{eq}), T k}\right)}\right],
$$

where $L_{\mathrm{EP}, \mathrm{d}}$ is an 8 -h daily sound average and the $L_{\mathrm{A}(\mathrm{eq})}$ is the A-weighted equivalent continuous sound level for an interval of time $T$ corresponding to the type of noise $k$ that the person is exposed to during $T$ hours per day (7).

Considering that in the worst situation, a lecturer would spend $4 \mathrm{~h}$ in the Pre-clinic, $1 \mathrm{~h}$ in the Gypsum Laboratory and $2 \mathrm{~h}$ in the Clinic and that a student would spend $2 \mathrm{~h}$ in the Pre-clinic, $1 \mathrm{~h}$ in the Gypsum Laboratory and $2 \mathrm{~h}$ in the Clinic, we found that the daily noise exposure (lecturers and students) was $L_{\mathrm{EP}, \mathrm{d}}$ from 85 to $90 \mathrm{~dB}(\mathrm{~A})$.

European legislation limits daily noise exposure to $85 \mathrm{~dB}(\mathrm{~A})$ (7). A new European directive (8) which will take effect on February 2006, decreases the limit to $80 \mathrm{~dB}(\mathrm{~A})$. From the results found in this study the 


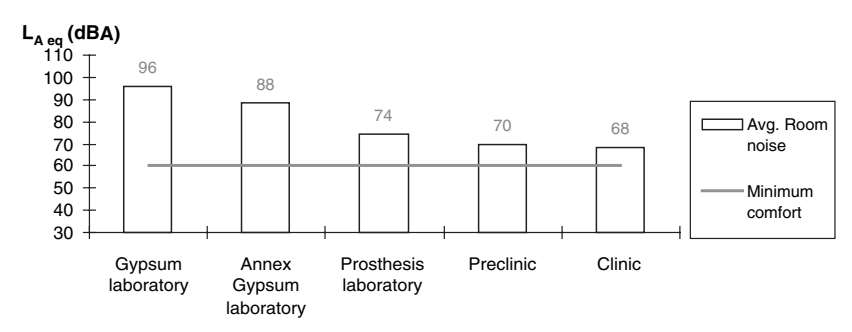

Fig. 3. Average noise level in each room (at $1 \mathrm{~m}$ ) and suggested maximum sound level for minimum comfort.

noise exposure of the lecturers and students are never lower than $85 \mathrm{~dB}(\mathrm{~A})$, in the best situations.

Even if the values are below the risk of hearing loss, the sound levels are high enough to consider setting limits. As these are learning-teaching areas $75 \mathrm{~dB}(\mathrm{~A})$ is suggested for the daily personal noise exposure as a limit for minimum acoustic comfort. To achieve this goal, sound levels should be reduced by at least $10 \mathrm{~dB}(\mathrm{~A})$. However, for ideal acoustic comfort, the maximum value of $70 \mathrm{~dB}(\mathrm{~A})$ for the global $L_{\mathrm{EP}, \mathrm{d}}$ is suggested, thus sound levels should be reduced by $15 \mathrm{~dB}(\mathrm{~A})$.

However, if we compare the measured sound levels (Table 2) to some European limits (Fig. 3), none of the measured values would comply with these laws. The European legal limits for equipment sound level in learning-teaching areas varies from $L_{\mathrm{A}} \leq 46 \mathrm{~dB}(\mathrm{~A})$ in Portugal, to $L_{\mathrm{A}} \leq 40 \mathrm{~dB}(\mathrm{~A})$ in Italy, to $L_{\mathrm{A}} \leq 38 \mathrm{~dB}(\mathrm{~A})$ in France or $L_{\mathrm{A}} \leq 35 \mathrm{~dB}(\mathrm{~A})$ in Sweden and $L_{\mathrm{A}} \leq$

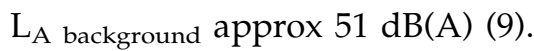

As the existing legislation is not adjusted to these learning-teaching areas in dental schools, it is logical to suggest a limit in this type of areas, where the sound levels are higher than in other schools (10).

Taking into account the value of $60 \mathrm{~dB}(\mathrm{~A})$ suggested by the Portuguese Noise Code (10) for the sound level limit in places where concentration and quiet are needed and the value of $56 \mathrm{~dB}(\mathrm{~A})$ considered for relaxed communication at a normal tone at $3 \mathrm{~m} \mathrm{(4),} \mathrm{the}$ sound level of $60 \mathrm{~dB}(\mathrm{~A})$ as the maximum limit at any time for this type of areas would seem appropriate $(7,10)$.

The effects of noise on learning have been researched in other learning-teaching areas. The results of previous studies show that noise annoyed and adversely affected mental performance (concentration and visual perception), particularly in persons sensitive to low-frequency noise that is defined as broadband noise with dominant content of low frequencies $(10-250 \mathrm{~Hz})$ (11). We would like to point out the importance of noise reduction in Pre-clinical and
Clinical areas because high-level noise exposure is likely to be relatively continuous in such settings, especially for lecturers and students. Although, in a learning context, background noise and interruptions adversely affect the ability to learn (12). In dental learning areas (Laboratories, Pre-clinic and Clinic areas) background noise exists because equipment was used continuously or intermittently. The amount of mental work carried out decreased with high background noise, thus it would be appropriate to lower it (13).

\section{Conclusion}

Learning-teaching activities in dental schools are carried out in a noise polluted environment. Although the sound levels are below that which causes damage to the human ear $[85 \mathrm{~dB}(\mathrm{~A})]$, a necessary reduction of exposure in sound levels is required for acoustic comfort. Reducing the sound level of noise sources [by 4-7 $\mathrm{dB}(\mathrm{A})]$ can be obtained by regular maintenance, early repairs, replacement of defective items and use of newer less noisier models or by increasing the sound absorption of the room [where a decrease of 3$5 \mathrm{~dB}(\mathrm{~A})$ is possible]. By these measures it would be possible to reduce the noise levels by $7-12 \mathrm{~dB}(\mathrm{~A})$ and thus achieving a minimum level of comfort for these learning areas.

\section{References}

1. Bahannan S. Noise level of dental handpieces and laboratory engines. J Prosthet Dent 1993: 70: 356-360.

2. Setcos JC, Mahyuddin A. Noise levels encountered in dental clinical and laboratory practice. Int J Prosthodont 1998: 11: 150-157.

3. Clark WW, Bohne BA. Effects of noise on hearing. JAMA 1999: 281: 1658-1659.

4. Cavanaugh WJ. Architectural acoustics. Principles and practice. New York: J. Wiley \& Sons, 1999: 36-39, 111-112.

5. Lehto TV, Laurikainen ETA, Aitasalo KJ, Pietilä TJ, Helenius HYM, Jonhasson R. Hearing of dentists in the long run: a 15-year follow-up study. Comm Dent Oral Epidemiol 1989: 17: 207-211.

6. Altinoz HC, Gokbudak R, Bayraktar A, Belli S. A pilot study of measurement of the frequency of sounds emitted by high-speed dental air turbines. J Oral Sci 2001: 43: 189-192.

7. Law DR 9/92 of April 28. European directive 86/188/ CEE of May 12, 1986. Lisbon: INCM, 1987.

8. European directive 2003/10/CEE of February 6, 2003. Brussels.

9. Vallet M, Karabiber Z. Some European policies regarding acoustical comfort in educational buildings. Noise Control Engl J 2002: 50: 58-62. 
10. Law DL 129/2002, of May 11. Regulamento dos Requisitos Acústicos dos Edifícios (Portuguese Noise Code for Buildings). Lisbon: INCM, 2002.

11. Pawlaczk-Luszcynska M, Dudarewicz A, Waszkowska M, Szymczak W, Kamedula M, Sliwinska-Kowalska M. The effect of low frequency noise on human mental performance. Med Pr 2004: 55: 63-74.

12. McDonald DD, Wiczorek M, Walker C. Factors affecting learning during health education sessions. Clin Nurs Res 2004: 13: 156-167.

13. Umemura M, Honda K, Kikuchi Y. Influence of noise on heart rate and quantity of work in mental work. Ann Physiol Anthropol 1992: 11: 523-532.
Address:

$M^{a}$ Mercedes Gallas

Stomatology Department

Facultad de Medicina y Odontología

Rua Entrerríos, S/N

Santiago de Compostela, C.P. 15782

A Coruña, Spain

Tel: +34 981563100 (ext. 12415)

Fax: +34 981562226

e-mail: mmgallas@usc.es 